\title{
A Collaborative Framework for Web based Vocational Education and Training (VET); Findings from a Case Study
}

\author{
Irum Inayat \\ Computer Science \& Information Technology faculty of University of Malaya, Malaysia. \\ Email:irum@siswa.um.edu.my \\ Rooh ul Amin \\ Automation School of Northwestern Polytechnical University, China. \\ Email:rooh@mail.nwpu.edu.cn \\ Zubaria Inayat \\ Computer Science department of Comsats Institute of Information Technology, Pakistan. \\ Email:zinayat@gmail.com \\ Khan Badshah \\ Automation School of Northwestern Polytechnical University, China. \\ Email:khan_phys@yahoo.com
}

\begin{abstract}
The growing need of trained human capital for economic empowerment and growth has increased the trend of vocational training through elearning, worldwide. It serves as a major source of training professionals, technicians, skilled workers and students who are unable to carryout formal college education due to time, cost and distance. In this paper we have discussed several cases from literature that made use of e-learning based vocational education and training. Later we have proposed a collaborative framework for vocational education and training using e-learning on the basis of findings from the literature. The framework has been practically implemented in a real world case study and findings revealed that factors like student-student and student-teacher collaboration, individual assessment of students, availability of adequate support material aid in enhancing students' performance and learning outcomes.
\end{abstract}

Index Terms - E-learning, Vocational Education and Training (VET), Collaborative Framework.

\section{INTRODUCTION}

E-learning provides a potential alternative to the traditional and conventional learning methods by using internet and web technologies ${ }^{[1]}$. Learners' communication among each other and with instructor is possible through synchronous and asynchronous artifacts like email, chat forums, message boards ${ }^{[2]}$. The interactive electronic user interfaces, Learning Management Systems [3], and Content Management systems ${ }^{[4]}$ and have outperformed the previously used one way communication methods like CD ROMS.

Collaboration in E-Learning is not only limited to communication and knowledge sharing ${ }^{[5]}$. It is shared creation of ideas and accomplishment of work ${ }^{[6,7]}$. This paper describes the formulation of a collaborative framework for e-learning based Vocational Education and Training (VET). We have selected nine cases from literature discussing implementation of VET in different domains which later on guided the formulation of our proposed collaborative framework. The proposed framework equips the user with shared problem solving skills, collaboration in work with independent study and assessment. This makes e-learning closer to the real world classroom study.

This paper is divided into several sections such as: section 1 is about the introduction of topic, section 2 explains the literature review, section 3 described the formulation of proposed framework and case studies discussion based on literature, section 5 explains the proposed framework, and section 6 concludes the paper.

\section{LITERATURE REVIEW}

E-learning for VET makes use of information and communication technologies and knowledge management mechanisms ${ }^{[2]}$. To combat the economic inflation trained workforce is one of the biggest resources. Vocational education aids in increasing the number of skilled workers, thus helps in gaining economic stability and eradication of unemployment. Elearning based vocational education and training has widely been adopted by universities, poly technique 
colleges, skill based institutes and industrial homes in order to gain momentum in terms of skilled work force. VET through e-learning is practiced widely in developed countries like Australia with students from foreign lands i.e. India and China ${ }^{[8]}$. This shows that in present day world learning does not rely on physical proximity of training centers and laboratories ${ }^{[9]}$.

Vocational education and training is basically a career and technical education specific to some craft or profession and includes skill based training courses. Vocational education and trainings are offered at a level after k-12 or Intermediate level education or even few Poly technique colleges offer courses and diplomas after $10^{\text {th }}$ standard/O levels or Matriculation Exam and falls under tertiary education category. This education often comes.

VET using e-learning owes equal importance in the development of a state and economic growth ${ }^{[8,9]}$. The VET courses provide skill to the learned people in order to enhance their professional abilities [9-11]. These certifications and diplomas help the masses to earn jobs improve wages and defines career for them. The UNESCO's Second International Conference suggested that the VET of the future not only prepares individuals for employment but also make them responsible citizens which is important to preserve integrity of environment and the welfare of others ${ }^{[12]}$.

\section{TOWARDS THE FRAMEWORK FORMULATION; CASE STUDIES DISCUSSION}

In this section we have discussed nine cases from literature which made use of e-learning for VET in different domains and for people from different walks of life. The basic purpose of this discussion is to deduce the important features of VET for various domains. A summarized view of all cases is presented below in Table 1.
TABLE 1: Discussion of Cases Implementing ELearning based VET

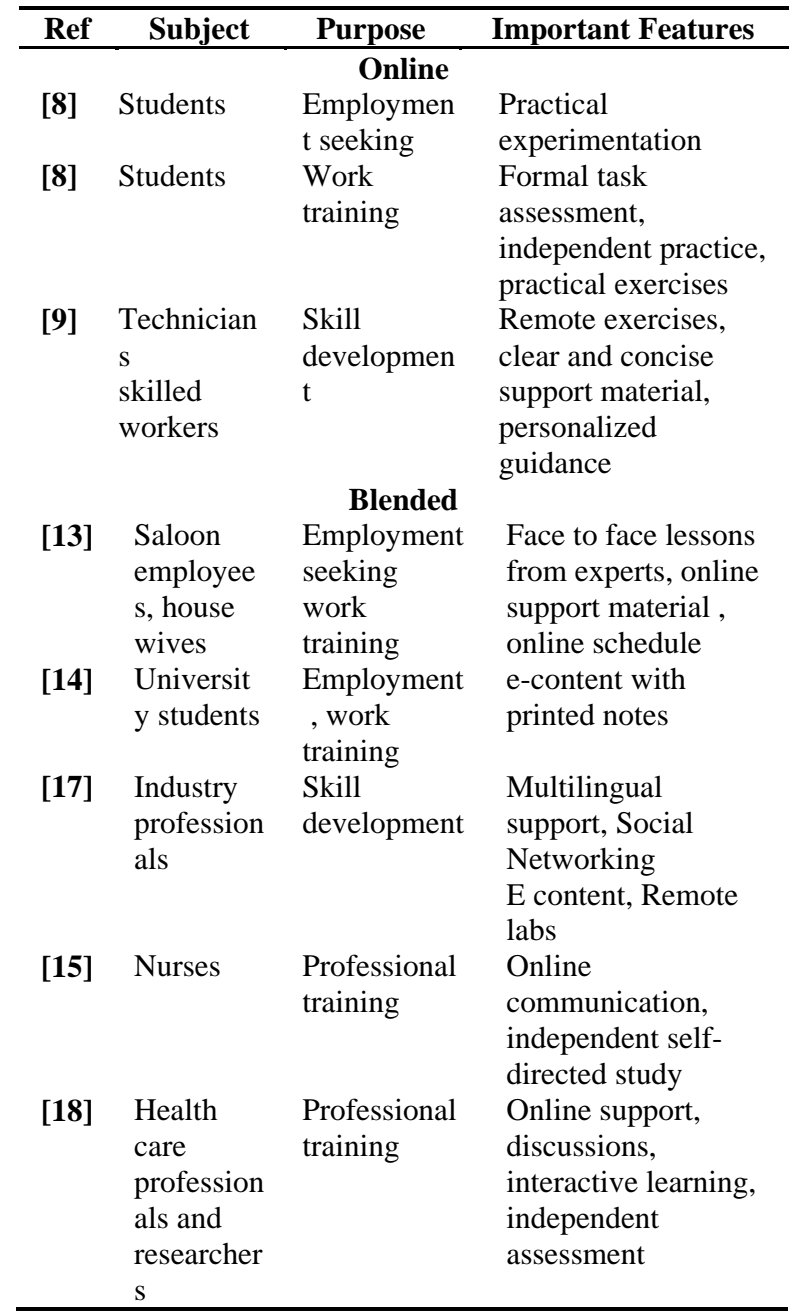

\section{A. Case 1 Interior Design Course ${ }^{[8]}$}

A program was designed for students to carry out design assignments for an avatar customer in 3-D space. The 3-D space made it close to real environment. The findings proved that students who performed these experiments performed better than the rest.

\section{B. Case 2 Diploma of Alcohol and Drugs [8}

A diploma was offered to train the students to administer the client assessment tool and report the level of seriousness of patients. This kind of applications use heavy use of face to face learning but in this case responses showed that e learning mechanism proved successful.

\section{Case 4 Certification in ICT [9]}

ICT certifications comprising Internet/intranet technology NGN Protocols, Information security, IPv6, and Network security, were offered for students. Blended mode was used to support content was available on web and in the form of printed booklet. Exercises were given to students and monitored using interactive interfaces. Exams are monitored using exam editor a web based application that keeps log of every 
activity and change committed to databases. The study concluded that students appreciated the online availability of course content.

\section{Case 3 Diploma of Beauty and Spa Therapies [13]}

An online course of electrolysis and electrical was designed in Moodle for beauty therapists and workers. The exam and quizzes were designed using Articulate. Blended medium is used for both theory and practice. The findings reveal that the students appreciated the flexibility of online course due to factors like time, cost, distance and other social issues.

\section{E. Case 5 Training in Engineering [14]}

This training was organized to for skill development among industry professionals. The main aim of this course was to enhance sharing and collaboration among stakeholders from industry.

\section{F. Case 6 Training for veterinary nurses [15]}

This training was basically for veterinary nurses in which paper based exams were changed to LMS based quizzes and online lectures were provided to students. The response showed that this measure brought ease to the process and helped in speedy assessment.

\section{G. Case 7 Training in Mechatronics [17]}

The training was organized for both skilled technicians and unemployed people to enhance their professional skills through online learning systems. The students responded with satisfaction due to personalized learning system.

\section{H. Case 8 Training in Health Informatics [18]}

This training was organized for medical professionals, academia researchers to enhance their capabilities through online interaction with other scholars. This course helped the professionals with e-learning tools, eglossaries and offline availability of courseware. The users showed their confidence in learning methods due to interactive communication and interactive learning through experience methods.

\section{A COLLABORATIVE FRAMEWORK FOR E- LEARNING BASED VET}

The above discussion about case studies following elearning for VET in various domains invited us to formulate a comprehensive framework for collaboration oriented e-learning based VET. It is observed from the above discussion that communication among users and instructors, interactive learning, e-assessment, online availability of support content are some of the features which were highly appreciated. Communication over issues, sharing views, solving problems together and seeking from others experience makes E-learning closer to face-to-face class based environment. The literature proves that collaboration in terms of knowledge sharing and discussion is helpful for students in e-Learning environment to improve their learning outcomes and satisfaction ${ }^{[19] .}$ The proposed framework (shown in Fig. 1 ) is derived from the features of VET supported by elearning practical experiences (described in Section III).

The framework comprises of three conceptual layers or tiers. In the first tier we have focused on the elementary and mandatory features with which every web based VET systems should be equipped. These skills are based on both individual and collaborative work including individual problem solving skills, individual learning skills, teamwork skills, and collaborative problem solving skills. The second layer of the proposed framework comprises of the tools support for the features mentioned in layer 1 . The tools support includes self-study and assessment tool, collaboration tool, team assessment tool, team responsibility analysis, multi-language support tool. The description of the functionalities foreseen from these tools is described in Table 2. The third layer comprises of front end applications.

It is inferred from the literature that the main characteristics of an e-learning based VET system are such as: collaboration, individual Problem Solving Skills, and Independent Learning Skills. To incorporate these skills in an e-learning system tools support is mandatory. The detailed description of our proposed framework focusing on tool support is shown in table 2 below.

The framework provides a repository of online and up to date course support material in terms of online lectures, video lectures, tutorials, solved examples and simulations for enabling the user to strengthen expertise through self-study support tool. The framework offers collaboration with individual assessment and learning features. The learners can make use of quizzes and practice exercises which help them to drill the lessons and assess their expertise though self-assessment tool. It is intended to assess the individuals on the basis on their group activity and individual expertise both through individual accountability tool which enables the instructor to examine each learner individually. The team responsibility tool helps to assess the individuals even in group assignments and projects through common online editors. The online grading helped the students not only to receive feedback instantly but also serves a high cut in cost. The assignments, tests and quizzes are checked online and grades are places in grade books subsequently. This way the students are provided with an opportunity to improve their mistakes as per feedback. The framework provides collaborative support to learners through discussion using chat, messages and emails. The online forum discussion board which facilitates teacher-student interaction and inter-student interaction provides the instructor with an opportunity to monitor the discussions and get a broader idea about their problems. This also improves students' interest in course and their due devotion. Considering the intent of providing language flexibility the framework offers multi language support and glossary of frequently used terms. 


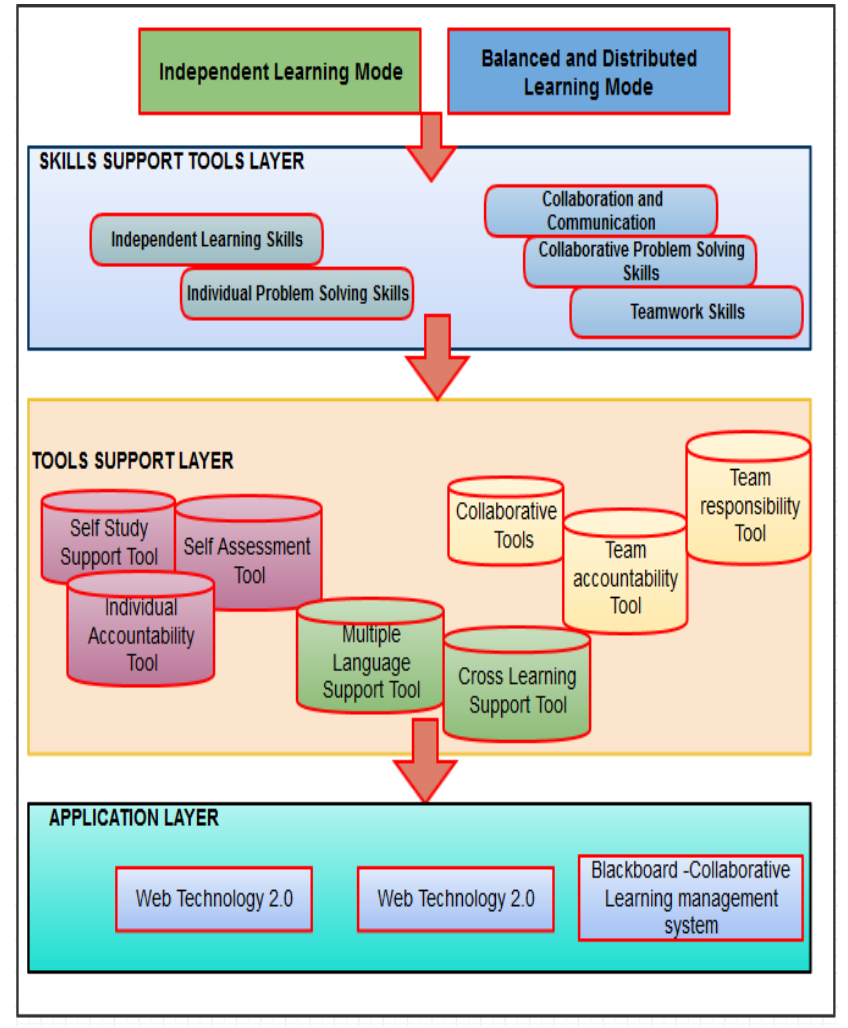

Figure. 1: Collaborative Framework for E Learning based VET

\section{CASE STUDY}

We conducted a case study at a vocational educational and training institute of Pakistan to practically evaluate the feasibility of our conceptual framework. Three consecutive sessions of web design course were studied for this purpose.

The learning content management system (LCMS) Black board Learning Platform ${ }^{1}$ was used for presenting the course.

\section{A. Participants}

One hundred seventy six students were examined to illustrate the aspects of proposed framework. There were 61,49 and 66 participants in three consecutive sessions.

\section{B. Course Structure}

The course was designed to develop individual and collaborative learning and problem solving skills in students. The students were assigned group projects and assessed on the basis of their individual effort. There were ten assignments and three projects contributing $25 \%$ to the total score.
TABLE 2: Details of the proposed Framework

\begin{tabular}{|c|c|}
\hline \multicolumn{2}{|c|}{ Self-Study Support Tool } \\
\hline Support Material & $\begin{array}{l}\text { Lessons, lecture notes, solved } \\
\text { examples, simulations, } \\
\text { presentations with voice, video } \\
\text { lectures and tutorials in native } \\
\text { language available online and } \\
\text { can be downloaded. }\end{array}$ \\
\hline \multicolumn{2}{|c|}{ Self-Assessment Tool Support } \\
\hline Self-assessment & $\begin{array}{l}\text { Quizzes and practice exercises } \\
\text { with grades and solutions. }\end{array}$ \\
\hline \multicolumn{2}{|c|}{ Individual Accountability Tool } \\
\hline $\begin{array}{l}\text { Individual } \\
\text { Accountability } \\
\text { measures }\end{array}$ & $\begin{array}{l}\text { Individual presentations on } \\
\text { assigned topics. Oral exam by } \\
\text { mentor or instructor. Online } \\
\text { tasks or assignments submitted } \\
\text { individually. In a group task } \\
\text { participation of individual in } \\
\text { tracked and graded }\end{array}$ \\
\hline \multicolumn{2}{|l|}{ Cross learning tool } \\
\hline $\begin{array}{l}\text { Cross learning } \\
\text { measures }\end{array}$ & $\begin{array}{l}\text { Flexible course, instructor, team } \\
\text { mates and language selection }\end{array}$ \\
\hline \multicolumn{2}{|c|}{ Team Responsibility Tool } \\
\hline $\begin{array}{l}\text { Common online } \\
\text { editors }\end{array}$ & $\begin{array}{l}\text { For assignments and class tasks } \\
\text { with administrator having } \\
\text { access through login } \\
\text { information of each user } \\
\text { determining each ones } \\
\text { contribution with time. }\end{array}$ \\
\hline \multicolumn{2}{|c|}{ Multi Language Tool } \\
\hline $\begin{array}{l}\text { Multi language } \\
\text { measures }\end{array}$ & $\begin{array}{l}\text { Language selection for } \\
\text { instruction if available and } \\
\text { translation feature for } \\
\text { documents with a dictionary of } \\
\text { frequently used terms. }\end{array}$ \\
\hline \multicolumn{2}{|c|}{ Collaboration Tools } \\
\hline $\begin{array}{l}\text { Collaborative } \\
\text { measures } \\
\text { Discussion Forum }\end{array}$ & $\begin{array}{l}\text { Communication with team } \\
\text { members, field experts, seniors. } \\
\text { Learn and practice together } \\
\text { through exercise editors. Share } \\
\text { pictures and documents. }\end{array}$ \\
\hline Traceability & To track down the activities log \\
\hline Storage & Storing the activity log \\
\hline Shared calendar & $\begin{array}{l}\text { For virtual teams for keeping up } \\
\text { with deadlines and schedule }\end{array}$ \\
\hline Document Security & $\begin{array}{l}\text { Sharing with permission only } \\
\text { and password protected files }\end{array}$ \\
\hline Mobility & $\begin{array}{l}\text { Interacting with people using } \\
\text { mobile phones, PDA and other } \\
\text { hand held devices. }\end{array}$ \\
\hline
\end{tabular}

\section{Methods and Procedures}

The response of students in terms of learning outcome and satisfaction was recorded through a post course questionnaire based survey. The questionnaire was based on likert scale questions. The participants were asked to fill the questionnaires in one week prior to examination week. The main aim was to record the most out of participants' memory and perception about the experiences they have recently been through.

\section{Discussion and results}

The likert scale responses of questionnaire and students' scores for the web design course show the 
feasibility of our proposed framework. The questionnaire along mean and standard deviation of responses is shown in table 3 .

TABLE 3: Questionnaire used for survey

\begin{tabular}{|c|c|c|}
\hline Questions & Mean & SD \\
\hline \multicolumn{3}{|l|}{ Instructor's Feedback } \\
\hline $\begin{array}{l}\text { The instructor was knowledgeable } \\
\text { about the course. }\end{array}$ & 1.49 & 0.75 \\
\hline $\begin{array}{l}\text { The instructor participated actively in } \\
\text { this course. }\end{array}$ & 1.46 & 0.77 \\
\hline $\begin{array}{l}\text { The instructor's feedback stimulated } \\
\text { you towards better performance. }\end{array}$ & 1.41 & 0.83 \\
\hline $\begin{array}{l}\text { The instructor's feedback discouraged } \\
\text { you ever. }\end{array}$ & 2.47 & 0.77 \\
\hline $\begin{array}{l}\text { The instructor was welcoming towards } \\
\text { your queries. }\end{array}$ & 1.20 & 0.65 \\
\hline $\begin{array}{l}\text { The instructor provided timely } \\
\text { feedback. }\end{array}$ & 1.35 & 0.68 \\
\hline $\begin{array}{l}\text { The instructor gave you personalized } \\
\text { feedback/guidance when requested. }\end{array}$ & 1.33 & 0.64 \\
\hline $\begin{array}{l}\text { The instructor feedback enhanced your } \\
\text { learning experience. }\end{array}$ & 1.42 & 0.70 \\
\hline \multicolumn{3}{|l|}{ Support Material } \\
\hline $\begin{array}{l}\text { The usability of the course portal was } \\
\text { satisfactory i.e. clear, user friendly. }\end{array}$ & 1.39 & 0.67 \\
\hline The course objectives were clear. & 1.49 & 0.75 \\
\hline $\begin{array}{l}\text { The course material was organized into } \\
\text { logical and understandable parts. }\end{array}$ & 1.43 & 0.72 \\
\hline $\begin{array}{l}\text { The course outline was up to the } \\
\text { expectations. }\end{array}$ & 1.44 & 0.76 \\
\hline $\begin{array}{l}\text { The support material was helpful in } \\
\text { real. }\end{array}$ & 1.33 & 0.64 \\
\hline $\begin{array}{l}\text { The support material was good enough } \\
\text { to cover course outlines. }\end{array}$ & 1.40 & 0.69 \\
\hline $\begin{array}{l}\text { The support material helped you in } \\
\text { clear understanding of course. }\end{array}$ & 1.47 & 0.72 \\
\hline $\begin{array}{l}\text { The support material enhanced your } \\
\text { learning experience. }\end{array}$ & 1.32 & 0.63 \\
\hline \multicolumn{3}{|l|}{ Group Activity } \\
\hline $\begin{array}{l}\text { The group assignments/tasks enhanced } \\
\text { your learning experience. }\end{array}$ & 1.31 & 0.60 \\
\hline $\begin{array}{l}\text { Participants cooperated in group } \\
\text { assignments/tasks in real sense. }\end{array}$ & 1.44 & 0.73 \\
\hline $\begin{array}{l}\text { The communication during group } \\
\text { activities is up to the mark. }\end{array}$ & 1.41 & 0.78 \\
\hline $\begin{array}{l}\text { The group assignments/tasks provide } \\
\text { an opportunity to learn from others. }\end{array}$ & 1.38 & 0.80 \\
\hline $\begin{array}{l}\text { The concept of team work will be } \\
\text { helpful for you in future job. }\end{array}$ & 1.33 & 0.78 \\
\hline $\begin{array}{l}\text { The group assignments/tasks are well } \\
\text { carried out by participants. }\end{array}$ & 1.45 & 0.74 \\
\hline $\begin{array}{l}\text { The group assignments/tasks are well } \\
\text { assessed and marked by instructor. }\end{array}$ & 1.40 & 0.67 \\
\hline $\begin{array}{l}\text { The group activity enhanced your } \\
\text { learning experience. }\end{array}$ & 1.43 & 0.70 \\
\hline
\end{tabular}

The response shows that the respondents agreed with the fact that instructor's feedback, adequate support material and collaborative work have enhanced their learning experience. The exam was based on a 48 question test and the results for all three sessions (Fall 10, Spring 10 and Fall 11) are shown in Table 3 and mean of scores is illustrated in fig. 2 below.

The mean graph shows an increase in average scores in each session. This assures the maturation of system with time. The case study shows that the proposed framework has improved the learning process, out come and experience of the students. In addition, the application of framework is highly feasible for enabling the learners to have modularized learning.

TABLE 4: Detail exam score of three sessions

\begin{tabular}{lccccccc}
\hline Session & Students & $\begin{array}{c}\text { Mean of } \\
\text { Correct }\end{array}$ & $\begin{array}{c}\text { SD of } \\
\text { correct }\end{array}$ & High & Low & Median & $\begin{array}{c}\text { Avg. Absolute } \\
\text { Deviation from } \\
\text { Median }\end{array}$ \\
\hline $\mathbf{1}$ & 61 & 25 & 6.7 & 42 & 10 & 24 & 5.4 \\
$\mathbf{2}$ & 49 & 26.1 & 6.5 & 41 & 10 & 27 & 5.1 \\
$\mathbf{3}$ & 66 & 27.8 & 5.6 & 39 & 10 & 28 & 4.3 \\
\hline
\end{tabular}


The modularized learning offers course material to the user with respect to his need, also known as buffetstyle courses. The personalized course drills and exercises have immensely improved students' interest in course and helped them in gaining deeper understanding. The results of these three sessions are then compared to the results of several previous years.

The comparison illustrated in fig. 3 below, shows that there is an increase in number of students, highest scores students achieved in exam and range of maximum score secured has also increased.

\section{CONCLUSION}

Web based e-learning used for VET is very important for economic growth. This paper states a collaborative framework for web based e-learning in VET deduced from literature. The student-student and student-teacher collaboration enhances the learning experience through communication and cooperation in problem solving. This collaboration makes virtual world of e-learning close to the real class environment. In addition, the student learns from team experience which is beneficial than independent study mode. The framework incorporates collaboration with individual assessment tool so that every student is graded according to his personal efforts. The findings reveal that students' results have improved throughout the course of time after implementing the proposed framework.

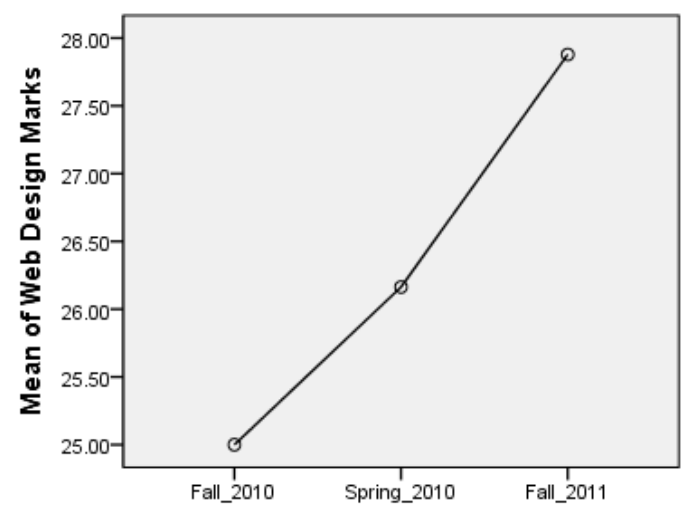

Figure. 2 Mean of scores for three sessions

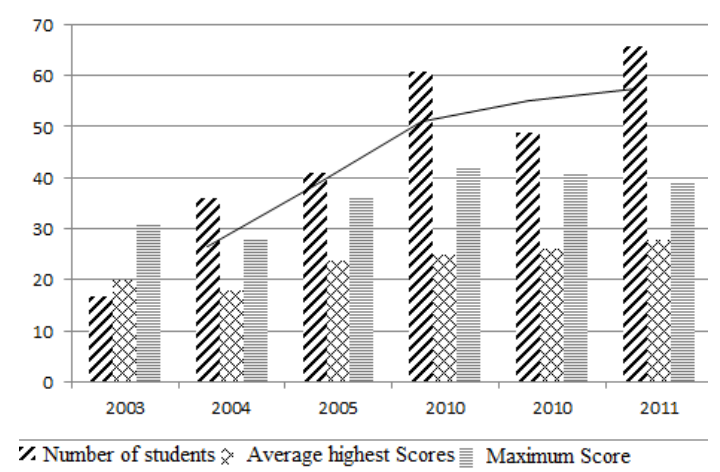

Figure. 3: Comparison of Results ${ }^{[19]}$

\section{ACKNOWLEDGEMENTS}

The authors are highly grateful to the respondents for their cooperation in making this research possible. Also, we would like to thank the institute for providing us with the opportunity to conduct this research.

\section{REFERENCES}

[1] Mark Nicholas, "E-Primer Series No. 1: ELearning in Context Mark Nichols E-learning specialist Laidlaw College", Auckland, NewZealand, 2008, pp.9-12.

[2] Pituch, K.A. \& Lee, Y.-K., "The influence of system characteristics one-learning use," Computers \& Education, 47, 2006, 222-244

[3] Organization for Economic Co-Operation and Development, "E-learning in Tertiary Education; Policy Brief”, Prepared by Public Affairs Division, 2005.

[4] Bergstedt, S, Wiegreffe, S, Wittmann, J, and Moller, D., "Content management systems and elearning systems -a symbiosis?," Advanced Learning Technologies, 2003 , pp. 155- 159.

[5] Borges. M., Araujo, R. O, "Groupware use in software development: short course ", Brazilian Symposium of Software Engineering, 13, Electronic Proceedings, 1999.

[6] Wolfgang Emmerich, "Working with User Stories", Workshop on Agile Requirement Engineering, ECOOP'11, 2011.

[7] Nitzke, J. A. Carneiro, M. L. F., Geller, M.; Santarosa, L. C. Criação, "Collaborative Learning Environments ", Brazilian Symposium on Computer Education, 1999.

[8] Sian Lewis and Brad Beach, "E-Learning Learning from Vocational Education in Victoria, Australia", 2011.

[9] Guiying Guo, Qinglong Zhan, and Guangran Liu; "Construction of a Training Model of Vocational Skills in Information Technology Environment," Computer Network and Multimedia Technology, 2009. pp. 1-4.

[10] OECD. Centre for Educational Research and Innovation, "E-Learning in tertiary education: where do we stand?" , 2005, pp: 21-29.Available at http://www.oecd.org/dataoecd/54/60/34899939. pdf

[11] Nichols, M., \& Anderson, B, Strategic e-learning implementation. Educational Technology \& Society, 2005, 8 (4), pp: 1-8.

[12] Athanase, N., Jiang Cangru, Li Hongbing, and Chen Zhihua., "Organizational E-learning Strategies for Technical and Vocational Education and Training (TVET) in Sub-Sahara Africa," Computer Science and Software Engineering, 2008, 5, pp.267-270.

[13] Melanie Brown, "Beauty and blended learning: Elearning in vocational Programs", Waikato 
Institute of Technology, Proceedings Ascilite Melbourne, 2008.

[14] Rojko, A, Jezernik, K, and Pester, A, "International E-PRAGMATIC network for adult engineering education , Global Engineering Education Conference , IEEE, 2011 ,pp $34-39$.

[15] E-assessment case study: Vocational training for veterinary nurses March 2010 www.flexiblelearning.net.au/files/BNIT_animal_s ciences_final.pdf

[16] Wen, Ling-Yu, Hsu, Shun-Fa, Chen, Shiu-Yu, and $\mathrm{Wu}$, Jun-Yen, "Application of a blended elearning method in designing a training program for developing professional competences of university teachers: e-CBT Model," Educational and Network Technology (ICENT), 2010 , pp.6670.

[17] Rojko, A.; Hercog, D, and Jezernik, K.,"Realization and experience of professional mechatronics e-training", E-Learning in Industrial Electronics, ICELIE '09, 2009, pp: 151-156.

[18] Kitsiou, S, Vlachopoulou, M., and Manthou, V, "IMPROHEALTH II: Web Based Virtual Quality Center for Vocational Education and Training in Health Informatics," Computer-Based Medical Systems, CBMS '07, 2007, pp.675-680, Available at http://www.nwlink.com/ donclark/hrd/ bloom.html

[19] Irum Inayat, Rooh ul Amin, Zubaria Inayat, and Siti Salwah Salim, "Effects of Collaborative Web Based Vocational Education and Training (VET) on Learning Outcomes", Computers \& Education, Volume 68, October 2013, pp. 153-166.

Irum Inayat: Doctoral research student at Department of Software Engineering, Faculty of Computer Science and Information Technology University of Malaya, Malaysia. Her research interests are web-based elearning, requirements engineering, agile software development developmemt methods.

Rooh ul Amin: Doctoral research student at, School of Automation, Northwestren Polytechnical University, Xi'an, China with research interests in control and automation and use of statistical analysis and automation theory in multi-disciplinary applications.

Zubaria Inayat: Graduate research student at Department of Computer Science, Comsats Institute of Information Technology, Islamabad, Pakistan, majoring in software porcess improvement.

Khan Badshah: Doctoral research student at, School of Automation, Northwestren Polytechnical University, Xi'an, China. 